\title{
CMIP5 temperature biases and 21st century warming around the Antarctic coast
}

\author{
Christopher M. LITTLE, ${ }^{1}$ Nathan M. Urban ${ }^{2}$ \\ ${ }^{1}$ Atmospheric and Environmental Research, Inc., Lexington, MA 02421, USA \\ E-mail: clittle@aer.com \\ ${ }^{2}$ Los Alamos National Laboratory, Computational Physics and Methods (CCS-2), Los Alamos, NM 87545, USA
}

\begin{abstract}
Projections of ice-sheet mass balance require regional ocean warming projections derived from atmosphere-ocean general circulation models (AOGCMs). However, the coarse resolution of AOGCMs: (1) may lead to systematic or AOGCM-specific biases and (2) makes it difficult to identify relevant water masses. Here, we employ a large-scale metric of Antarctic Shelf Bottom Water (ASBW) to investigate circum-Antarctic temperature biases and warming projections in 19 different Coupled Model Intercomparison Project Phase 5 (CMIP5) AOGCMs forced with two different 'representative concentration pathways' (RCPs). For high-emissions RCP 8.5, the ensemble mean 21st century ASBW warming is $0.66,0.74$ and $0.58{ }^{\circ} \mathrm{C}$ for the Amundsen, Ross and Weddell Seas (AS, RS and WS), respectively. RCP 2.6 ensemble mean projections are substantially lower: $0.21,0.26$, and $0.19^{\circ} \mathrm{C}$. All distributions of regional ASBW warming are positively skewed; for RCP 8.5, four AOGCMs project warming of greater than $1.8^{\circ} \mathrm{C}$ in the RS. Across the ensemble, there is a strong, RCP-independent, correlation between WS and RS warming. AS warming is more closely linked to warming in the Southern Ocean. We discuss possible physical mechanisms underlying the spatial patterns of warming and highlight implications of these results on strategies for forcing ice-sheet mass balance projections.
\end{abstract}

KEYWORDS: Antarctic glaciology, climate models, ice/ocean interactions, ice sheet mass balance

\section{INTRODUCTION}

In the 21 st century, changes in the mass balance of Antarctic ice shelves are expected to be driven largely by basal melting (Joughin and others, 2012; Pritchard and others, 2012). Because ice shelves are hundreds of meters thick, these changes must be driven by the circulation or hydrographic properties of the deepest water on the continental shelf (Jacobs and others, 1992; Pritchard and others, 2012). The properties of this water mass, termed Antarctic continental shelf bottom water (ASBW) by Schmidtko and others (2014), vary widely around Antarctica, but can be roughly segregated into two regimes. In the first regime, epitomized by the larger continental shelves in the Ross and Weddell Seas (RS and WS, respectively), bottom waters are formed locally and influenced strongly by sea ice processes (Loose and others, 2009; Nicholls and others, 2009), resulting in a water mass (high-salinity shelf water, or HSSW) that is very close to the surface freezing point. In contrast, bottom water in the Amundsen Sea (AS) is largely composed of relatively unmodified Circumpolar Deep Water (CDW), with temperatures up to $1.8^{\circ} \mathrm{C}$ (Jacobs and others, 1996, 2011; Dutrieux and others, 2014; Schmidtko and others, 2014). The origins and physical processes involved in the formation and modification of these water masses might suggest that different regimes are unlikely to respond similarly to climate change; indeed, while the AS is suspected to have warmed over the past few decades and exhibits strong interannual variability over the (limited) observational record (Dutrieux and others, 2014), cold-regime shelf seas have not (although there is a significant freshening trend in many locations (Jacobs and others, 2002; Jullion and others, 2013; Schmidtko and others, 2014)).

Atmosphere-ocean general circulation models (AOGCMs) constitute the primary tool for projections and are required to relate global changes to local bottom water temperature, however, they cannot currently resolve all the small-scale processes driving ASBW properties (e.g. Arthun and others, 2013; St-Laurent and others, 2013; Dinniman and others, 2015; Kjellsson and others, 2015; Nakayama and others, 2014). Understanding biases and spread in AOGCMs is thus critical, both for developing projections that account for uncertainty as well as informing downscaling techniques that relate large-scale changes in ocean hydrography to basal melting.

Other studies have assessed AOGCM ocean warming projections of relevance to Antarctica. Yin and others (2011) employed 19 CMIP3 AOGCMs, finding a mean circumAntarctic warming of $\sim 0.5^{\circ} \mathrm{C}$ at $200-500 \mathrm{~m}$ depth. Levermann and others (2014) use CMIP5 output to calculate regional 21 st century warming over four oceanic sectors; the full AOGCM range is then used with additional models to relate ocean temperature to ice mass balance. Neither of these studies investigates biases or meridional variability in warming. Sallée and others (2013) use a potential-density based water mass definition to examine CMIP5 southern ocean biases and warming. Although the comparison with a depth-based analysis is indirect, their CDW class shows ensemble mean warming $\left(<0.5^{\circ} \mathrm{C}\right)$ that is comparable with the CMIP3 ensemble (Yin and others, 2011). They also note the presence of a warm bias $\left(\sim 0.4^{\circ} \mathrm{C}\right)$ in the ensemble mean CDW. However, it is unclear whether this bias or warming is coherent near the coast. Others have analyzed sea floor temperature (Heuze and others, 2013, 2015), but bathymetry varies across AOGCMs and continental shelves in some regions may not be resolved, making the relevance of these projections to ice shelves unclear.

In this paper, we: (1) develop a AOGCM-based metric of coastal subsurface ocean temperature that is relevant to ice 
shelves and allows comparison with observations, (2) quantify the spread in bias and warming in the CMIP5 ensemble using that metric; and (3) examine the relationship of regional and large-scale warming within AOGCMs and across the ensemble. The results provide a baseline for assessing the utility of coarse-resolution AOGCMs for ice sheet mass balance projections and revisit some of the implicit assumptions in previous work (e.g. averaging regions and spatial correlation).

\section{METHODS}

\section{AOGCM output}

We analyze temperature biases and future warming using an ensemble of 19 CMIP5 AOGCMs (Table 1; see also http:// cmip-pcmdi.llnl.gov/cmip5/). Each of these AOGCMs simulates the mid-19th century to 2005 climate forced by a common evolution of historical atmospheric composition. Here, we analyze potential temperature ('thetao') fields over 1986-2005 (the baseline period) and anomalies from this baseline. We examine two future (2006-2100) warming pathways forced with: RCP 2.6, a pathway, which implies dramatic emissions reductions in the 21 st century; and RCP 8.5, a high-end business-as-usual emissions pathway. For each RCP, we use a single realization ('r1i1p1') from each AOGCM. CMIP5 ocean models use a variety of curvilinear grids, which we interpolate to a common $1^{\circ} \times 1^{\circ}$ grid for gridded analyses shown here. To analyse biases and warming at the coast, we use the native grid, as discussed in the following section.

Biases over the baseline period are presented relative to the World Ocean Atlas, 2013 edition (WOA13; Locarnini and others (2013)) on a $1^{\circ} \times 1^{\circ}$ grid. Although there are apparent differences in the WOA13 and recent cruise-based and moored measurements (e.g. in the AS), it is unclear whether this result is due to missing data or the interpolation scheme. Our limited analysis of supplementary observational datasets is supported by our results showing AOGCM bias is large relative to potential errors in the observational dataset.

\section{ASBW temperature metric}

We select 273 equivalently spaced points along the Antarctic coastline as defined in the BEDMAP2 project (Fretwell and others, 2013) (filled circles in Fig. 1a). The ASBW temperature of each CMIP5 AOGCM (and the WOA13) is the temperature of the deepest grid cell at the location - on each AOGCM's native grid - that is closest to each coastal point, subject to two conditions (required due to the widely varying coastline and bathymetry at the AOGCM resolution (Fig. 1b)). These conditions are: (1) a $400 \mathrm{~m}$ 'ceiling'; and (2) a $600 \mathrm{~m}$ 'floor', based on the typical depth range of the continental shelf break. If the depth of the closest grid point is shallower than $400 \mathrm{~m}$, the next closest grid point is used; if the closest grid point exceeds $600 \mathrm{~m}$ depth, ASBW is defined to be the mean potential temperature between 400 and $600 \mathrm{~m}$. Our analysis focuses on spatial averages of ASBW along coastal points in the AS (red points in Fig. 1a), Weddell Sea (WS, green points) and Ross Sea (RS, blue points).

\section{RESULTS}

\section{Ensemble results}

The CMIP5 ensemble mean Southern Ocean - south of $60^{\circ} \mathrm{S}$ and between 400 and $600 \mathrm{~m}$ depth - shows a cold bias (Fig. 2a; area-average $=-0.31^{\circ} \mathrm{C}$ ). Assuming this depth range represents $\mathrm{CDW}$, this result might be viewed as

Table 1. List of model simulations, and the circum-Antarctic root-mean-square ASBW bias and warming, for each AOGCM included in the ensemble. All use the ' $\mathrm{r} 1 \mathrm{i} 1 \mathrm{p} 1$ ' realization. Warming for each simulation is 2080-2099 mean relative to the 1986-2005 mean. All values in ${ }^{\circ} \mathrm{C}$

\begin{tabular}{|c|c|c|c|c|c|}
\hline \multirow[b]{2}{*}{ Modeling center } & \multirow[b]{2}{*}{ Model } & \multirow[b]{2}{*}{ No. } & \multirow[b]{2}{*}{$\begin{array}{l}\text { RMS } \\
\text { bias }\end{array}$} & \multicolumn{2}{|c|}{ Warming } \\
\hline & & & & $\begin{array}{l}\text { RCP } \\
2.6\end{array}$ & $\begin{array}{l}\mathrm{RCP} \\
8.5\end{array}$ \\
\hline Beijing Climate Center, China Meteorological Administration & BCC-CSM1.1 & 1 & 1.16 & 0.09 & 0.22 \\
\hline Beijing Climate Center, China Meteorological Administration & BCC-CSM1.1M & 2 & 1.04 & 0.12 & 0.30 \\
\hline Canadian Centre for Climate Modelling and Analysis & CanESM2 & 3 & 0.98 & 0.17 & 0.33 \\
\hline Centre National de Recherches Meteorologiques & CNRM-CM5 & 5 & 1.42 & 0.19 & 0.94 \\
\hline $\begin{array}{l}\text { Commonwealth Scientific and Industrial Research Organization in collaboration with } \\
\text { Queensland Climate Change Centre of Excellence }\end{array}$ & CSIRO-Mk3.6.0 & 6 & 0.94 & 0.12 & 0.53 \\
\hline NOAA Geophysical Fluid Dynamics Laboratory & GFDL-CM3 & 7 & 0.99 & 0.21 & 0.93 \\
\hline NOAA Geophysical Fluid Dynamics Laboratory & GFDL-ESM2M & 8 & 1.12 & 0.18 & 1.50 \\
\hline NOAA Geophysical Fluid Dynamics Laboratory & GFDL-ESM2G & 9 & 1.30 & 0.11 & 0.55 \\
\hline NASA Goddard Institute for Space Studies & GISS-E2-R & 10 & 1.01 & 0.26 & 0.87 \\
\hline Institut Pierre-Simon Laplace & IPSL-CM5A-LR & 12 & 1.10 & 0.07 & 0.09 \\
\hline Institut Pierre-Simon Laplace & IPSL-CM5A-MR & 13 & 1.14 & 0.02 & 0.19 \\
\hline $\begin{array}{l}\text { Japan Agency for Marine-Earth Science and Technology, Atmosphere and Ocean Research } \\
\text { Institute (The University of Tokyo), and National Institute for Environmental Studies }\end{array}$ & MIROC-ESM & 14 & 1.35 & 0.24 & 0.67 \\
\hline $\begin{array}{l}\text { Japan Agency for Marine-Earth Science and Technology, Atmosphere and Ocean Research } \\
\text { Institute (The University of Tokyo), and National Institute for Environmental Studies }\end{array}$ & $\begin{array}{l}\text { MIROC-ESM- } \\
\text { CHEM }\end{array}$ & 15 & 1.34 & 0.32 & 0.78 \\
\hline Max Planck Institute & MPI-ESM-LR & 16 & 1.18 & 0.12 & 0.41 \\
\hline Meteorological Research Institute & MRI-CGCM3 & 17 & 1.45 & 0.18 & 0.51 \\
\hline Norwegian Climate Centre & NorESM1-M & 18 & 1.00 & 0.48 & 0.90 \\
\hline Norwegian Climate Centre & NorESM1-ME & 19 & 0.98 & 0.46 & 0.96 \\
\hline
\end{tabular}



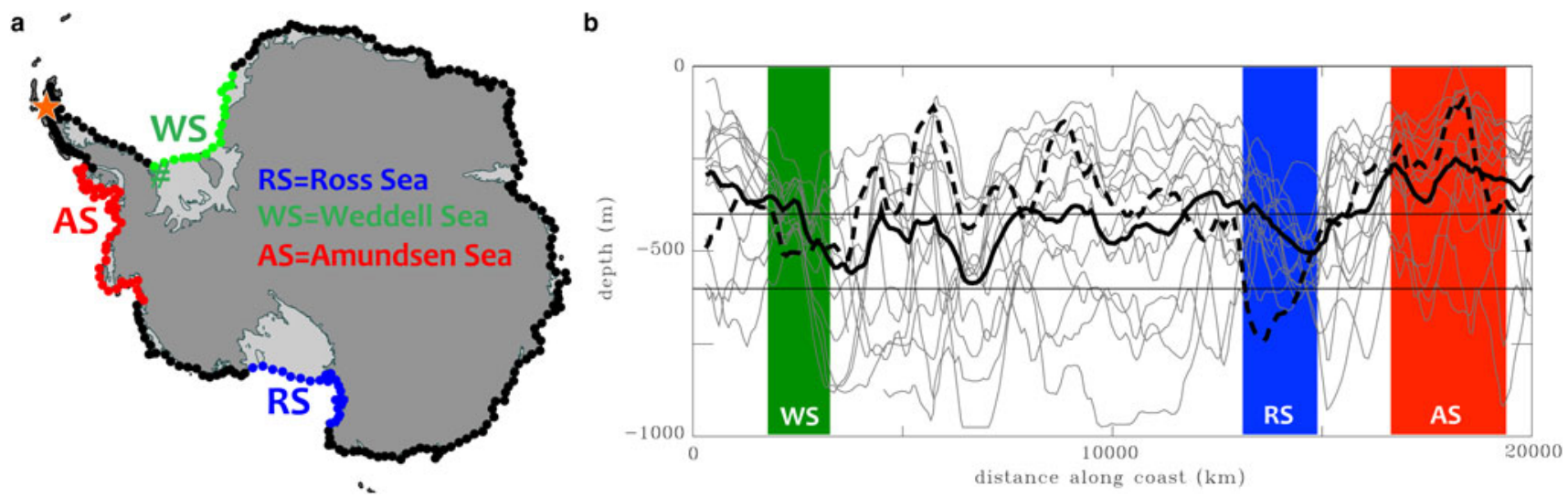

Fig. 1. (a) Antarctic coastline from the BEDMAP2 dataset, with ice shelves shown in light grey. 273 coastal points are shown with circles; red, green, and blue points correspond to the AS, WS and RS sectors, respectively. Orange star is the point corresponding to $x=0$ in subsequent plots. Distance increases clockwise along the coast. (b) Depth of sea floor at the closest native grid point from coastal locations. Black dashed line is from the WOA13 observations. Grey lines correspond to each of the 19 CMIP5 models. Solid black line is the CMIP5 ensemble mean.

contrasting with Sallée and others (2013), who find a slight warm bias. However, Sallee and others' definition of CDW is based on water mass properties at $30^{\circ} \mathrm{S}$, and biases are assessed with respect to the entire CDW volume. Although there are alternate explanations (e.g. the set of AOGCMs included in the ensemble), we suggest that our results are not inconsistent, given the meridional variability in the ensemble mean bias as shown in Figure 2a.

a

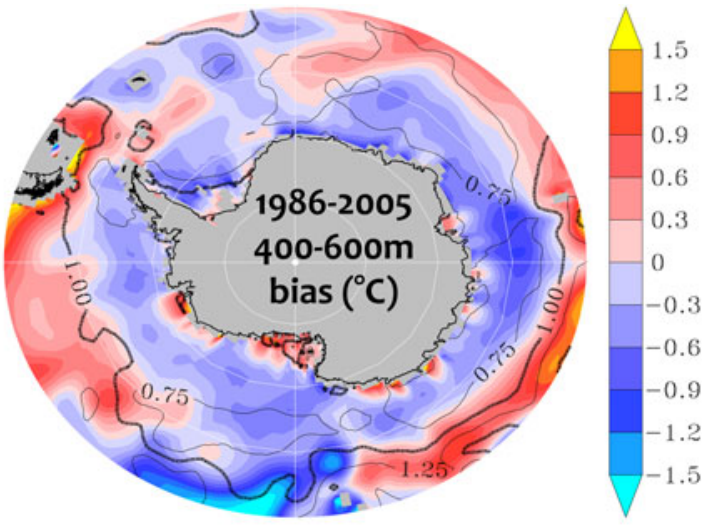

b

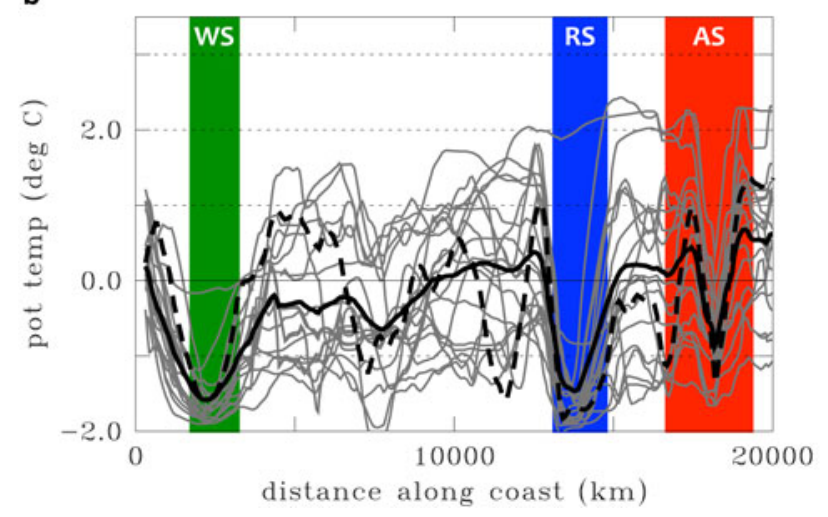

Fig. 2. (a) Ensemble mean temperature bias (1986-2005) relative to WOA13 depth-averaged over $400-600 \mathrm{~m}$. Contours show the ensemble standard deviation. (b) ASBW temperature along the Antarctic coast. Black dashed line is from the WOA13 observations. Grey lines correspond to each of the 19 CMIP5 models. Solid black line is the CMIP5 ensemble mean.
The zonally consistent cold bias does not persist at the coast (Fig. 2b), which is characterized by alternating warm and cold ASBW biases. AOGCM biases vary within the regions, which we analyze later in the paper, particularly the AS; indicating that water mass biases (and warming) are likely to be moderated by regional averaging.

As noted by Yin and others (2011) and Sallée and others (2013), projected Southern Ocean warming is muted closer to Antarctica (Fig. 3). In the ensemble mean, for both RCPs, offshore warming is enhanced in the Weddell Gyre relative to the Pacific Ocean and Ross Gyre. The ensemble spread, however (shown with the contours), is highest in the RS. The greater warming in the 400-600 $\mathrm{m}$ depth range in the Weddell Gyre is not evident in ASBW (Figs 3c, d), suggesting coastal processes, perhaps relating to sea ice, isolate and shield the coast. Along the coast, ensemble mean 21st century ASBW warming projections are quite uniform: approximately $\sim 0.25^{\circ} \mathrm{C}$ for RCP 2.6 for all three regions, increasing to $\sim 0.75^{\circ} \mathrm{C}$ in $\mathrm{RCP} 8.5$. The ensemble mean warming pattern obscures, however, AOGCM-specific differences in the ASBW warming pattern evident in Figures 3c, d and discussed in the following section.

\section{AOGCM-by-AOGCM results}

In Figure 4, biases and warming for the three coastal seas are analyzed by AOGCM. When averaged across the coastline, ASBW biases are far larger in the AS (17th-83rd percentile range of $\left.-1.2-0.56^{\circ} \mathrm{C}\right)$ and $\mathrm{RS}\left(0.13-1.17^{\circ} \mathrm{C}\right)$ than in the WS $\left(-0.11-0.38^{\circ} \mathrm{C}\right)$. The ensemble distribution is positively skewed in the RS and WS, driven by the floor imposed by the surface freezing point. All regions are characterized by outliers, which exhibit much larger biases than other AOGCMs; the MRI-CGCM and CNRM-CM5 set the high end of bias for the RS and AS (MRI-CGCM is also high in the WS); while the GISS-E2-R is the coldest model in all three seas.

For RCP 2.6, the warming in all three seas shows a similar distribution across AOGCMs, with a median of $\sim 0.25^{\circ} \mathrm{C}$ and no obvious outliers. The mean, median and inter-model variance in ASBW warming increase for RCP 8.5 (17th-83rd percentile range of $0.35-0.98^{\circ} \mathrm{C}$ in the AS, $0.06-1.94^{\circ} \mathrm{C}$ in the $\mathrm{RS}$, and $0.02-1.18^{\circ} \mathrm{C}$ in the WS). The projections are positively skewed, with the median projections lower than the 

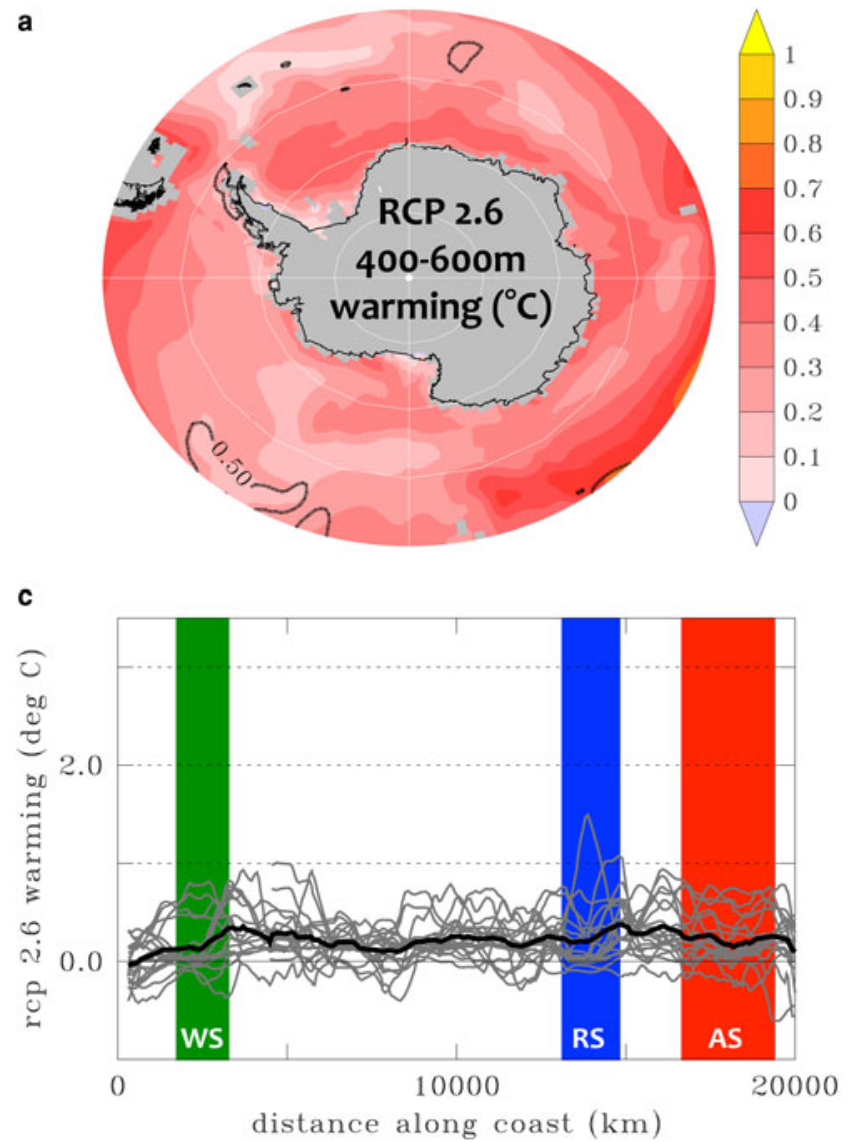
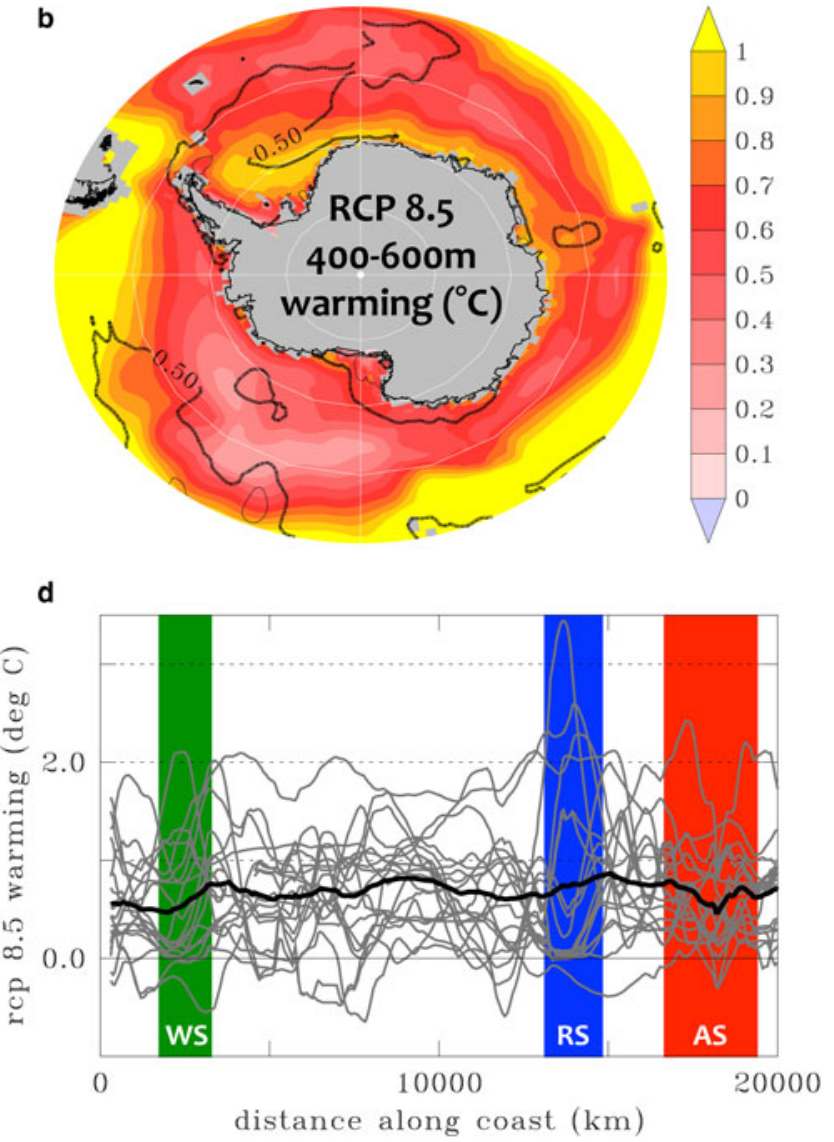

Fig. 3. (a) RCP 2.6 and (b) RCP 8.5 warming depth-averaged over 400-600 m (2080-2099 minus 1986-2005 baseline). Contours show the ensemble standard deviation. (c) RCP 2.6 and (d) RCP 8.5 ASBW warming along the Antarctic coast. Grey lines correspond to each of the 19 CMIP5 models. Solid black line is the CMIP5 ensemble mean.

mean as shown in Figure 3. Despite the lower RS median warming of only $\sim 0.2^{\circ} \mathrm{C}$, the RS is more vulnerable to high rates of 21 st century warming than other coastal seas, with an 83 rd percentile warming of almost $\sim 2.0^{\circ} \mathrm{C}$ (compared with $\sim 1^{\circ} \mathrm{C}$ in the AS and WS). In the AS and WS, models are approximately uniformly distributed within the central range, except for a few outliers, whereas the RS has three clusters of models.

Models with a large present-day bias tend to be outliers in the magnitude of coastal warming for RCP 8.5. MRI-CGCM, in particular, is at the low end of projections for the RS and AS; CNRM-CM5 has a significant positive bias in both and shows a high ASBW warming in the RS; GISS-E2-R has a significant negative bias and the highest warming in the AS.

The relationship of warming in different coastal seas across models is more evident in Figure 5. The MRI-CGCM and CNRM-CM5, indicated with circles, are not included in the regressions due to their significant biases, which we assume are related to the circulation and are a dominant influence on their climate response. When these outliers are removed, there is very little correlation between temperature biases and warming (not shown).

Regional correlations in subsurface warming around Antarctica are dependent upon the regions considered and the imposed climate forcing. Across AOGCMs, warming in the Ross and Weddell Seas is strongly correlated for both RCPs $\left(r^{2}>0.65\right)$. While RS and AS warming is correlated $\left(r^{2}=0.54\right)$ in RCP 2.6, the linkage is weak for RCP 8.5; RS ASBW warming is much larger (for four AOGCMs) relative to the AS under the stronger forcing. The strongest relationship between large-scale warming south of $60^{\circ} \mathrm{S}$ and ASBW warming is in the AS, but this is only evident for RCP $8.5\left(r^{2}=0.61\right)$. 'Cold regime' ice shelves exhibit weaker relationships with the Southern Ocean $\left(r^{2}<0.26\right)$. There is limited evidence for ensemble-wide correlations between regional ASBW warming and large-scale warming, either in the global mean or south of $60^{\circ}$.

\section{DISCUSSION}

By highlighting biases and warming in Antarctic shelf water masses, and investigating the correlation between regional and large-scale warming, these results can guide hypotheses regarding physical mechanisms underlying AOGCM warming patterns and their use in ensemble projections. These considerations are discussed separately below.

\section{Warming mechanisms}

Many processes, both local and non-local, have been found to control the subsurface heat balance of the Antarctic continental shelf. The focus has principally been on the winds: easterlies near the coast, which regulate mixing, transport and the depth of the pycnocline near the shelfbreak (Dinniman and others, 2012; Stewart and Thompson, 2015); and the strength and position of midlatitude westerlies, which regulate the large-scale water mass properties and position (horizontal and vertical) of relevant water 


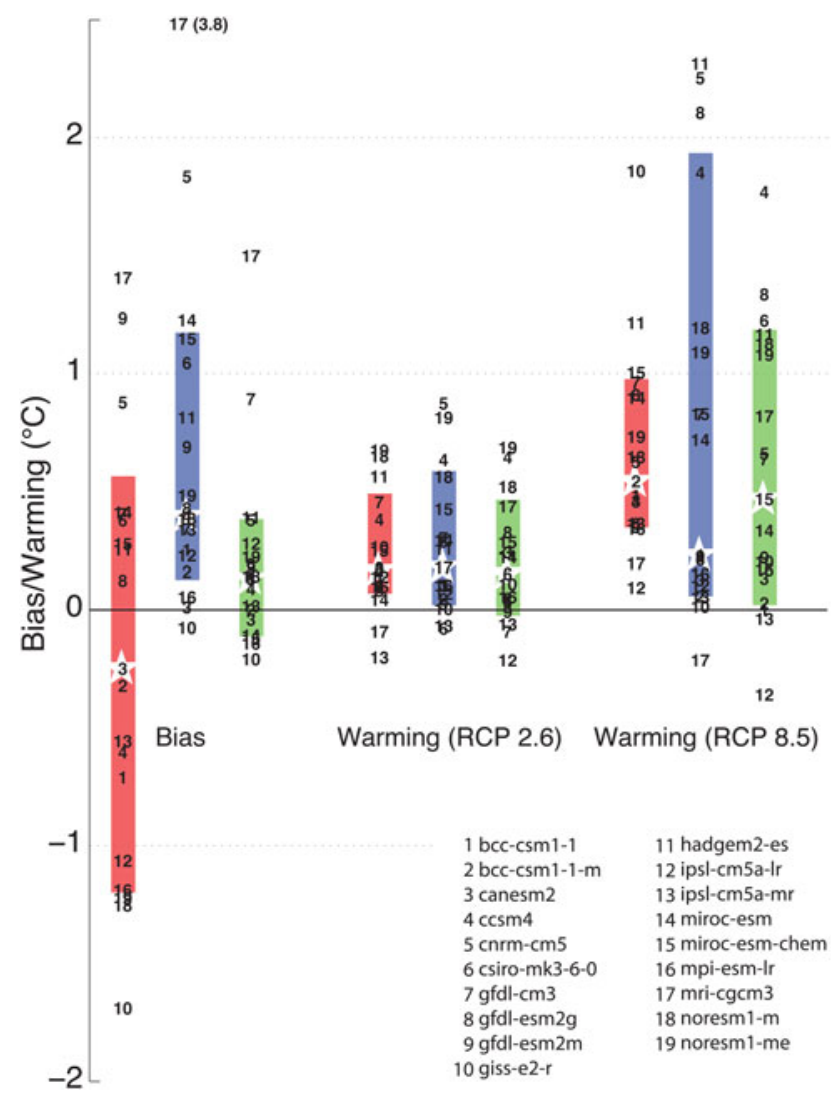

Fig. 4. ASBW temperature bias and warming, by model, averaged over the three sectors indicated in Figure 1. Stars indicate the ensemble median, bars correspond to the 17 th-83rd percentile range.

masses (Sallée and others, 2013). CMIP5 models exhibit a robust strengthening and southward shift in westerlies (Bracegirdle and others, 2013). This mechanism might be particularly relevant to warming in the AS, which is in close proximity to the ACC. However, Southern

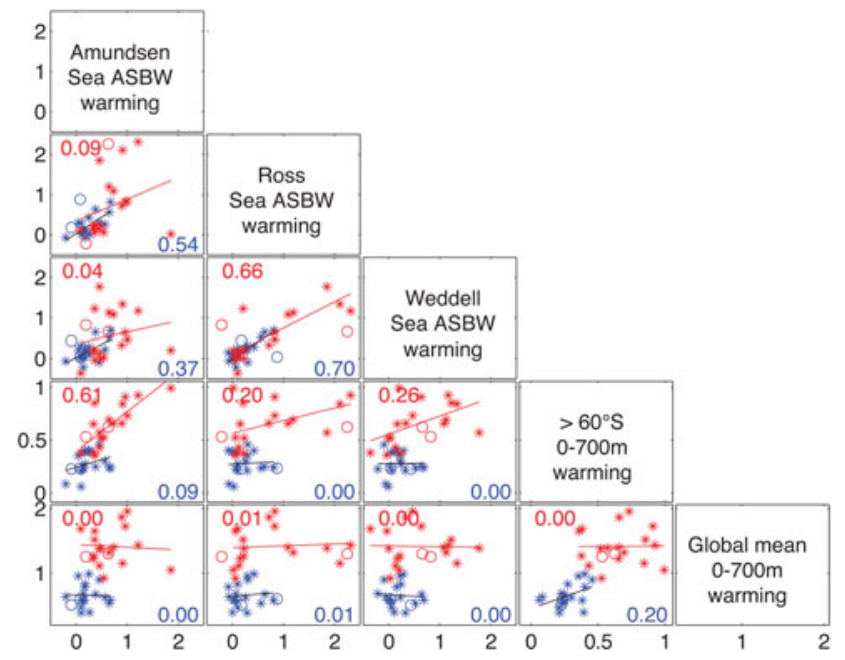

Fig. 5. Pairwise scatterplots of warming (2080-2099 minus 19862005 baseline) over different regions for each of 19 models in the ensemble. ASBW corresponds to the values in Figure 4. Southern Ocean and global mean warming is a $0-700 \mathrm{~m}$ average. RCP 2.6 is in blue; RCP 8.5 is in red. Numbers show the $r^{2}$ for a linear fit that excludes outliers (shown with open circles and discussed in the text).
Hemisphere winds, and the position of the AS Low (Raphael and others, 2015), are strongly governed by coherent modes of atmospheric variability, in particular, the Southern Annual Mode (SAM). The strong, robust, signal of an increasing SAM index in climate models (Gillett and Fyfe, 2013), particularly with stronger (RCP 8.5) forcing, may underlie subsurface warming, evident here across all regions. Consistent with this large-scale linkage, Spence and others (2014) have shown that a southward shift of the midlatitude westerlies weakens Antarctic easterlies and enhances on-shelf transport (Stewart and Thompson, 2015).

We look for signatures of these processes in vertical profiles of upper ocean warming in Figure 6. MRI-CGCM and HadGEM2 (shown with dashed grey lines) show surface-intensified warming, which differs greatly from the ensemble in the RS and AS. Ignoring these models, the vertical distribution of warming - but not its magnitude - is fairly consistent across the ensemble, with a limited degree of surface warming in the mixed layer, a subsurface minimum and a relatively monotonic increase below $\sim 100 \mathrm{~m}$ depth. Temperature profiles suggest the persistence of strong stratification (at least in the annual mean); warming, with the exception of the AS, is strongly confined to the deeper water masses. In addition to supporting our choice of the ASBW metric, the bottom-intensified warming, at rates that are often greater than at comparable depths off-shelf, suggests an increase (although model-specific) of on-shelf transport. Such a circumpolar response is consistent with a largescale change in surface stress. However, it does not exclude a role for sea ice or related processes on the RS or WS, which may moderate or govern their distinct response.

A more detailed mechanistic understanding of individual AOGCM warming is difficult to extract from this broad analysis. As a starting point, subsequent analyses might use changes in sea ice formation rates, salinity and/or seasonality to reveal whether changes in temperature are forced by changes in HSSW properties or CDW flux. Because atmospheric, sea ice and oceanic processes are tightly coupled in these regions (see, for example, the explanations of coastal change in Timmermann and Hellmer (2013), de Lavergne and others (2014) and Bintanja and others (2013), which invoke complicated feedbacks between atmospheric modes, freshening, sea ice, convection, stratification and the ice sheet), there is a need for a comprehensive assessment of the coupled system described by AOGCMs (Bracegirdle and others, 2015).

\section{Implications for ensemble projections}

Our results highlight three priorities for ensemble projections of ocean temperature and/or melting designed to provide climatic boundary conditions for ice-sheet models, ensembles, or intercomparisons (e.g. Bindschadler and others, 2013; Nowicki and others, 2013; Levermann and others, 2014) capturing coastal warming, including regional and global linkages, and assessing high-end AOGCMs in the RS.

\section{Capturing coastal warming}

As noted above, there are substantial challenges involved in the representation of Antarctic coastal processes in AOGCMs. However, capturing 'far-field' warming or averaging over large coastal and/or offshore regions (Yin and others, 2011; Sallée and others, 2013; Levermann and 

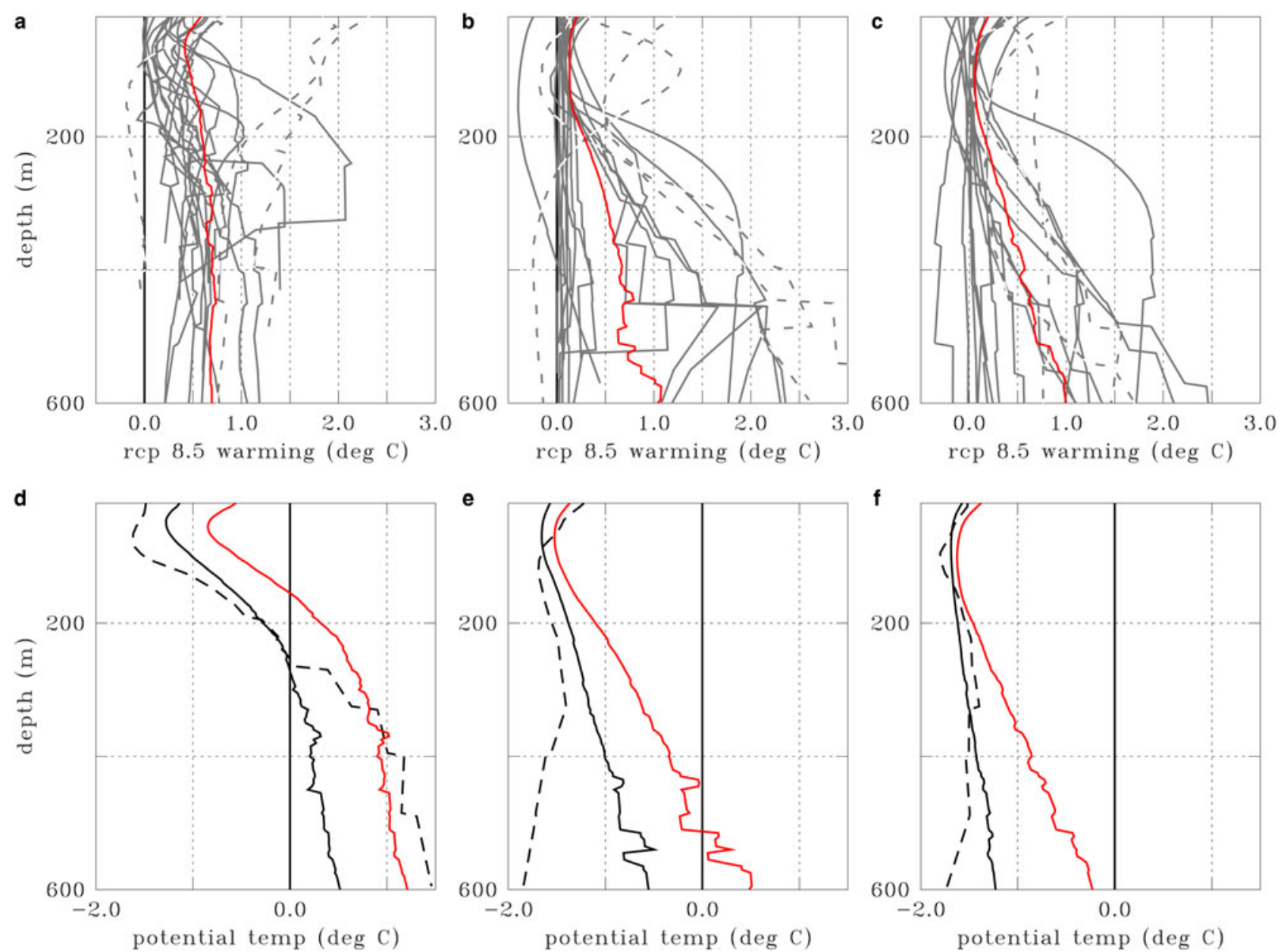

Fig. 6. Vertical profiles of warming in the (a) AS, (b) RS and (c) WS. Ensemble mean RCP 8.5 warming is shown with the red line, individual AOGCMs are shown in grey, and dashed lines show outlier models, described in the text. Vertical profiles of potential temperature for the AOGCM ensemble mean for 1986-2005 (black solid line), 2080-2099 (red solid line), and WOA13 (dashed black line) in the (d) AS, (e) RS and (f) WS.

others, 2014) is also problematic: there are continental shelf processes (e.g. buoyancy fluxes, winds and coastal currents) that are at least partially represented in AOGCMs. Here, these processes, or their representation in large-scale models, drive significant differences in biases and warming from that occuring in offshore regions. Furthermore, the meridionally tilt of isopyncals in the Southern Ocean, the (possibly related) meridional gradient in biases and warming evident in Figures 2a, 3a, c, and the large differences in regional coastal warming rates, implies that a single depth range (even one that varies as a function of ice shelf or continental shelf depth) may not be indicative of water masses relevant to ice shelves. Finally, we note that $\mathrm{AOGCMs}$ coarse resolution may influence model solutions well offshore - for example, via the parameterization of eddies and wind stress in regulating the thermocline depth and heat and volume transport (Screen and others, 2009; Farneti and others, 2010; Spence and others, 2014; Griffies and others, 2015).

Although continental shelves are narrow and subject to high along-coast variability, these issues are mitigated when averaging over large areas of the continental shelf. We thus suggest that it is important to restrict the northern boundary over which warming is assessed, and to use the native grid and bathymetry, so as to capture an AOGCM-specific representation of continental shelf. Such a strategy does, however, subject projections to the representation of coastal processes, which deserves further investigation.

\section{Including regional and global linkages}

In both RCPs, the RS and WS are characterized by a (correlated) model-dependent response that is largely unrelated to the global climate. We suspect these seas are influenced more by common physical processes, as discussed in the previous section (e.g. sea-ice, easterly wind changes and/or freshwater flux) than by regional circulation or global climate changes. An important question is whether the correlated warming across these large continental shelves is due to: (1) a common climate process (e.g. the important role of sea ice in their hydrography (Nicholls and others, 2009)) or (2) the treatment of these processes in models (Kjellsson and others, 2015).

In contrast, the warming of ASBW around coastal Antarctic seas is weakly correlated between the AS and the other two seas. As might be expected from observations, in which open ocean water masses are present on this shelf, CMIP5 models indicate that the strongest relationship between ASBW and the large-scale ocean temperature is in the AS, although the relationship decays substantially north of $60^{\circ} \mathrm{S}$. The theoretical basis for this is clear, with less extensive sea-ice cover and a likely connection to large-scale wind 

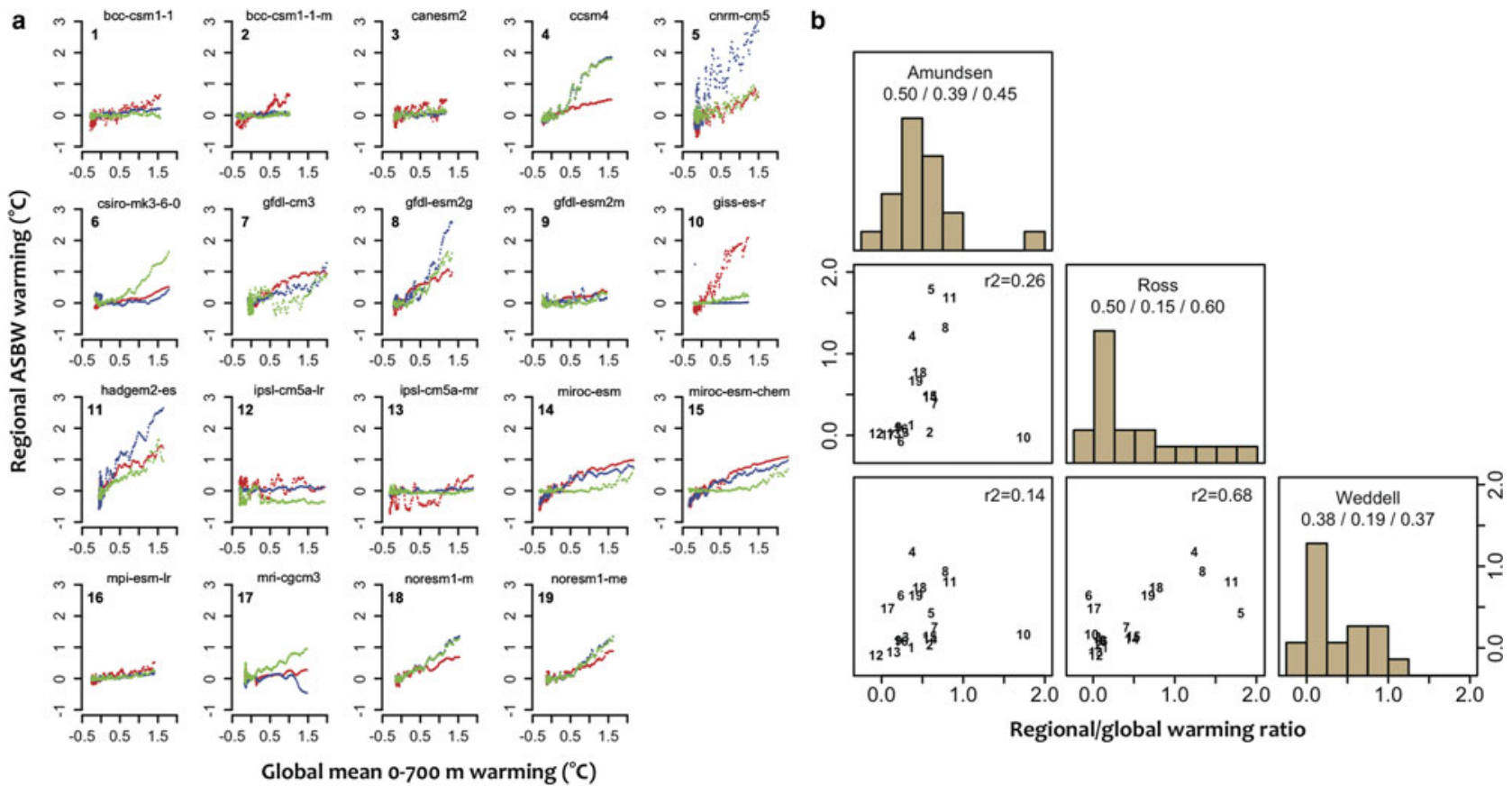

Fig. 7. (a) Pairwise scatterplots of annual mean warming over the 1860-2100 period (relative to 1986-2005 baseline) in each region ( $y$-axis) relative to the global mean 0-700 m warming (x-axis) for each of the 19 AOGCMs (RCP 8.5 simulation). Red, green, and blue points correspond to the AS, WS and RS sectors. (b) Scatter plots of the slope of the linear fit to the timeseries shown in (a) for each model across the three sectors. Numbers above the histograms are the mean/median/standard deviation of the linear fit slopes across the ensemble.

position and strength (Bracegirdle and others, 2013; Raphael and others, 2015) affecting both the temperature of the water masses and on-shelf transport.

Figure 5 shows almost no correlation between global and coastal ocean warming across the ensemble, which might suggest that we cannot downscale Antarctic coastal warming from global climate properties. However, such an analysis blurs the relationship between an $\mathrm{AOGCM}^{\prime}$ 's global heat uptake and the regional warming associated with a given heat uptake. In Figure 7a, we compare the full time series (1860-2100) of global and regional warming for each AOGCM for the three seas. Within most models, a linear function of a model's global ocean warming seems reasonably predictive of its regional warming, with internal variability about these linear relationships (most evident in the AS, but also evident amid the high RS warming in CNRM-CM5 and HadGEM2-ES). However, the slope of the linear relationship varies widely across models, as summarized in Figure $7 \mathrm{~b}$. Many of the models have weak warming in both the AS and the RS relative to their global ocean warming (low slopes for both seas), but there are also a number of models that have low AS warming but a wide range of higher RS warming (between $0.5 \times$ and $2 \times$ the rate of global ocean warming). Despite the wide spread among models, the linear relationships between the regional and global ocean warming suggest that a global energy balance model could predict the regional warming with reasonable skill by linearly downscaling its ocean heat projections, with some natural variability superimposed. There will be a different linear relationship for each AOGCM, which introduces multi-model uncertainty in the downscaling procedure.

\section{Assessing high-end AOGCMs}

This ensemble analysis indicates that ASBW in the RS is more vulnerable to high rates of warming than either the AS or WS.
This contrasts with Hellmer and others (2012), which indicates that the RS is less vulnerable to dramatic warming than the WS (note, however, that six AOGCMs included in this analysis exhibit WS warming of $>1^{\circ} \mathrm{C}$, and that Timmermann and Hellmer (2013) suggest evidence for rapid RS warming as well). While this finding merits further study of these individual models, it also may arise from general limitations of coarse resolution models near sharp subsurface temperature gradients. In the Southeast Pacific, the Antarctic Circumpolar Current intrudes relatively close to the coastline of Antarctica, with the AS exposed to relatively unmodified CDW. In contrast, the nearby RS exhibits only a mid depth intrusion of highly modified CDW (Loose and others, 2009), but is separated from warmer subsurface water masses by only a $O(10 \mathrm{~km})$ shelfbreak front (Whitworth and Orsi, 2006). In contrast, the WS is shielded by the Antarctic Peninsula and the expansive Weddell Gyre, and its thermal structure appears to be better represented at the coast (excluding the MRI-CGCM and GFDL-CM3) (Fig. 6f).

Of the AOGCMs which show high rates of warming in the RS two - the MRI-CGCM and CNRM-CM5 - show severe warm biases (Fig. 8). In the MRI-CGCM, the bias is largest in the RS, potentially due to a poor representation of bathymetry or wind stress curl (Bracegirdle and others, 2013; Hosking and others, 2013), which allows offshore water masses to intrude onto the continental shelf; in the CNRMCM5, the bias appears to be widespread in the Southern Ocean. These biases appear to drive to a muted (in the case of the MRI-CGCM) or dramatic (in the case of CNRMCM5) warming in RS ASBW.

The mechanism underlying high RS ASBW warming in the other three models - CCSM4, GFDL-ESM2G, and HadGEM2ES - is less clear. One possible explanation is a fresh (and warm) bias on the continental shelf. In the RS (Fig. 6e), the AOGCM ensemble mean does not reflect the layered structure and HSSW evident in observations. The lack of HSSW 

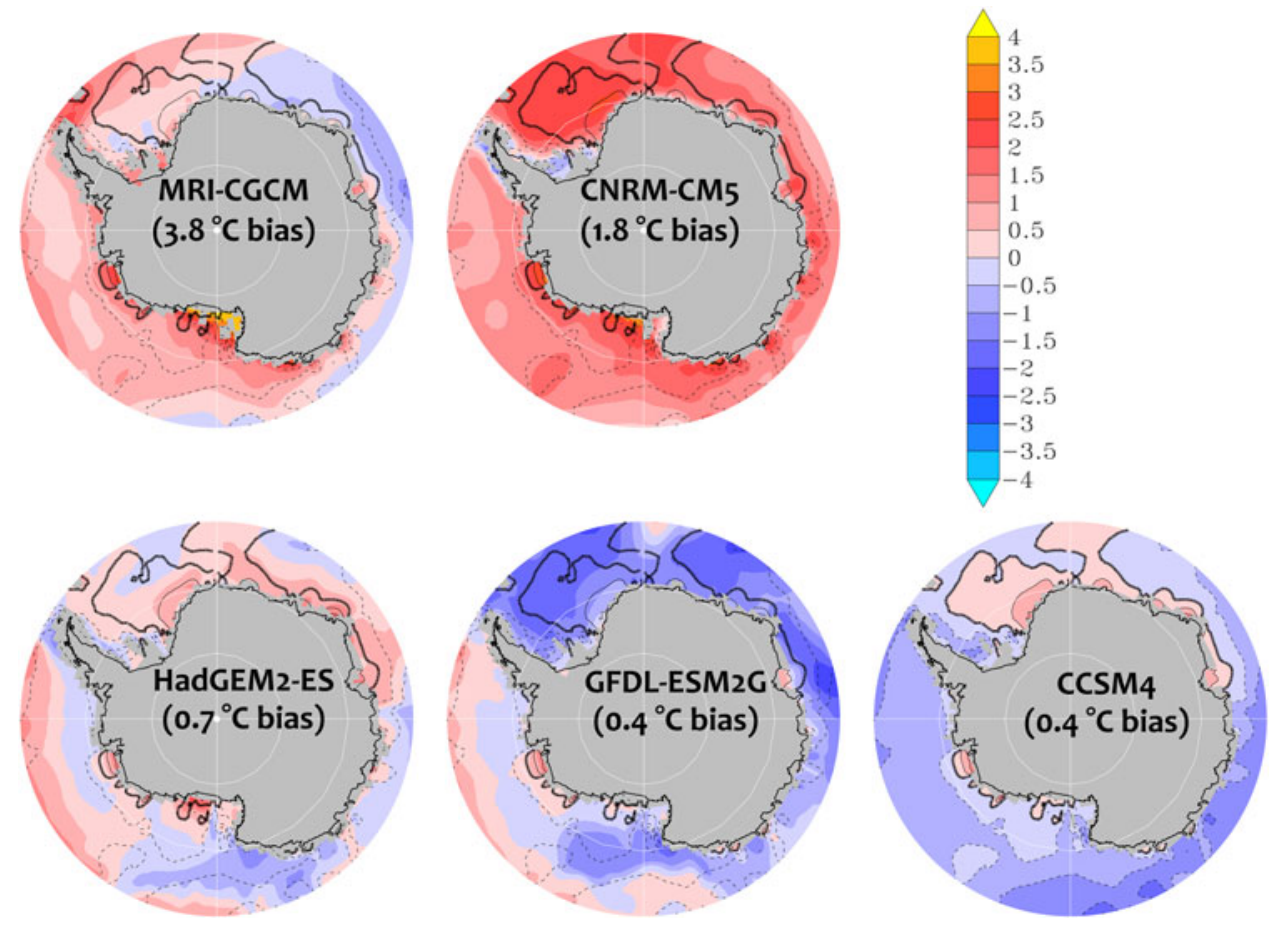

Fig. 8. Temperature biases, depth-averaged over 400-600 m, in individual models with anomalous 21 st century RS warming (cooling in the MRI-CGCM). Top 2 are 'outliers' in RS temperature bias; bottom 3 lie closer to the observations, and the ensemble mean bias.

may result from limited resolution, via its effects on coastal winds and sea ice production, or problems with sea ice physics (Timmermann and Hellmer, 2013; Turner and others, 2013; de Lavergne and others, 2014; Dinniman and others, 2015; Kjellsson and others, 2015; Shu and others, 2015). A light bias, independently or combined with changes in coastal buoyancy fluxes driven by freshening and/or sea ice trends, might predispose an AOGCM to the erosion of density fronts over the 21 st century (Hellmer and others, 2012; Timmermann and Hellmer, 2013; Kjellsson and others, 2015).

There remain other biases in AOGCMs that may influence ASBW properties, in the RS and elsewhere, over the century timescale. Regional freshwater fluxes from ice shelf and iceberg melting are systematically underestimated and may be poorly distributed, the circulation is influenced by smallscale dynamic barriers, and eddies and associated transports are not resolved (Arthun and others, 2013; St-Laurent and others, 2013; Cullather and others, 2014; Meijers, 2014; Nakayama and others, 2014; Shu and others, 2015). Furthermore, on-shelf transport is sensitive to the representation of the bathymetry. Figure 1 indicates significant spread and a shallow bias on much of the Antarctic continental shelf. We suggest, consistent with Nakayama and others (2014) and Hellmer and others (2012) that inadequate representation of bathymetric details is likely to underlie much of the systematic ASBW biases - both warm and cold - revealed in this analysis.

\section{CONCLUSIONS}

We have used a 19-member CMIP5 ensemble to calculate biases and 21st century warming of Antarctic Shelf Bottom Water, defined in a manner that accounts for coarse AOGCM resolution. We find ensemble mean warming by 2080-2099 in the AS, RS and WS of 0.66, 0.74 and $0.58^{\circ} \mathrm{C}$, respectively, for high-emissions RCP 8.5. RCP 2.6 ensemble mean projections are substantially lower: 0.21 , 0.26 and $0.19^{\circ} \mathrm{C}$. Across the ensemble, there is a strong, scenario-independent correlation between warming in the WS and RS. As forcing increases, the AS warming becomes less strongly correlated with the other two seas and more correlated with the Southern Ocean south of $60^{\circ} \mathrm{S}$. The RS has the largest spread in its 21 st century warming projections, with a $1 \sigma$ range of $\sim 0-2^{\circ} \mathrm{C}$. In almost all AOGCMs, warming is bottom-intensified, suggesting a change in the large-scale winds induces a change in on-shelf transport that may be moderated locally by processes related to sea ice production, or their representation in AOGCMs.

For fully-coupled simulations, large temperature biases may make it difficult to achieve a realistic initial ice-sheet state for future simulations. When constructing uncoupled, or 'offline', forcing scenarios, these results suggest that: (1) obvious biases should be used to exclude and/or deemphasize outlier models; (2) differences in near-coastal warming rates should be addressed, either using a sampling strategy (as employed here), or a separate parameterization; (3) RS and WS warming should be treated as correlated in ensemble projections; and (4) linear global/regional relationships suggest some predictability using a global energy balance model if it accounts for inter-AOGCM uncertainty in the linear relationship.

With the exception of a few models, there is no obvious relationship between the pattern of warming and biases. However, we suggest a deeper investigation is warranted, particularly in AOGCMs with enhanced RS subsurface warming. For future projections, it is worth considering exclusion, weighting, and/or bias correction of obvious outlier models; these AOGCMs have a meaningful quantitative impact on results if they are considered in projections. However, in keeping with the suggestions of Bracegirdle and others (2015), if metrics are to be employed for new 
intercomparsions and projections (e.g. CMIP6 and ISMIP6), they should be examined with a coupled, large-scale, perspective.

\section{ACKNOWLEDGEMENTS}

C.M.L is grateful for discussions with Laurie Padman, and financial support from NSF-PLR Award \#1513396. This research was also supported by the Regional and Global Climate Modeling program of the US Department of Energy Office of Science, as a contribution to the HiLAT project. The authors would like to thank the BEDMAP2 project and the developers of the Bedmap2 Toolbox for Matlab, and the NOAA Geophysical Fluid Dynamics Laboratory for data and analysis tools. We acknowledge the World Climate Research Programme's Working Group on Coupled Modeling, which is responsible for CMIP, and we thank the climate modeling groups (listed in Table 1) for producing and making available their model output. The U.S. Department of Energy's Program for Climate Model Diagnosis and Intercomparison provides coordinating support for CMIP and led development of software infrastructure in partnership with the Global Organization for Earth System Science Portals.

\section{REFERENCES}

Arthun M, Holland PR, Nicholls KW and Feltham DL (2013) Eddydriven exchange between the open ocean and a sub-ice shelf cavity. J. Phys. Oceanogr., 43(11), 2372-2387

Bindschadler RA and 27 others (2013) Ice-sheet model sensitivities to environmental forcing and their use in projecting future sea level (the SeaRISE project). J. Glaciol., 59(214), 195-224

Bintanja R, van Oldenborgh GJ, Drijfhout SS, Wouters B and Katsman CA (2013) Important role for ocean warming and increased ice-shelf melt in Antarctic sea-ice expansion. Nat. Geosci., 6(5), 376-379

Bracegirdle TJ, Emily and 7 others (2013) Assessment of surface winds over the Atlantic, Indian, and Pacific Ocean sectors of the Southern Ocean in CMIP5 models: historical bias, forcing response, and state dependence. J. Geophys. Res.: Atmos., 118(2), 547-562

Bracegirdle TJ and 18 others (2015) A multidisciplinary perspective on climate model evaluation for Antarctica. Bull. Am. Meteorol. Soc., 150904101253006

Cullather RI, Nowicki SMJ, Zhao B and Suarez MJ (2014) Evaluation of the surface representation of the Greenland Ice Sheet in a general circulation model. J. Clim., 27(13), 4835-4856

de Lavergne C, Palter JB, Galbraith ED, Bernardello R and Marinov I (2014) Cessation of deep convection in the open Southern Ocean under anthropogenic climate change. Nat. Clim. Change, 4(4), 278-282

Dinniman MS, Klinck JM and Hofmann EE (2012) Sensitivity of circumpolar deep water transport and ice shelf basal melt along the West Antarctic Peninsula to changes in the winds. J. Clim., 25 (14), 4799-4816

Dinniman MS and 5 others (2015) The effect of atmospheric forcing resolution on delivery of ocean heat to the Antarctic floating ice shelves*,+. J. Clim., 28(15), 6067-6085

Dutrieux P and 9 others (2014) Strong sensitivity of Pine Island IceShelf melting to climatic variability. Science, 343(6167), 174178

Farneti R, Delworth TL, Rosati AJ, Griffies SM and Zeng F (2010) The role of mesoscale eddies in the rectification of the Southern ocean response to climate change. J. Phys. Oceanogr., 40(7), 1539-1557
Fretwell P and 59 others (2013) Bedmap2: improved ice bed, surface and thickness datasets for Antarctica. Cryosphere, 7(1), 375-393

Gillett NP and Fyfe JC (2013) Annular mode changes in the CMIP5 simulations. Geophys. Res. Lett., 40(6), 1189-1193

Griffies SM and 12 others (2015) Impacts on ocean heat from transient mesoscale eddies in a hierarchy of climate models. J. Clim., 28(3), 952-977

Hellmer HH, Kauker F, Timmermann R, Determann J and Rae J (2012) Twenty-first-century warming of a large Antarctic iceshelf cavity by a redirected coastal current. Nature, $\mathbf{4 8 5}(7397)$, 225-228

Heuze C, Heywood KJ, Stevens DP and Ridley JK (2013) Southern Ocean bottom water characteristics in CMIP5 models. Geophys. Res. Lett., 40(7), 1409-1414

Heuze C, Heywood KJ, Stevens DP and Ridley JK (2015) Changes in global ocean bottom properties and volume transports in CMIP5 models under climate change scenarios*. J. Clim., 28(8), 29172944

Hosking JS, Orr A, Marshall GJ, Turner J and Phillips T (2013) The influence of the Amundsen-Bellingshausen seas low on the climate of West Antarctica and its representation in coupled climate model simulations. J. Clim., 26(17), 6633-6648

Jacobs SS, Hellmer HH, Doake CSM, Jenkins A and Frolich RM (1992) Melting of ice shelves and the mass balance of Antarctica. J. Glaciol., 38(130), 375-387

Jacobs SS, Hellmer HH and Jenkins A (1996) Antarctic ice sheet melting in the Southeast Pacific. Geophys. Res. Lett., 23(9), 957-960

Jacobs SS, Giulivi CF and Mele PA (2002) Freshening of the Ross Sea during the late 20th century. Science, 297(5580), 386-389

Jacobs SS, Jenkins A, Giulivi CF and Dutrieux P (2011) Stronger ocean circulation and increased melting under Pine Island Glacier ice shelf. Nat. Geosci., 4(8), 519-523

Joughin I, Alley RB and Holland DM (2012) Ice-sheet response to oceanic forcing. Science, 338(6111), 1172-1176

Jullion L and 5 others (2013) Decadal freshening of the Antarctic bottom water exported from the Weddell Sea. J. Clim., 26(20), $8111-8125$

Kjellsson J and 8 others (2015) Model sensitivity of the Weddell and Ross seas, Antarctica, to vertical mixing and freshwater forcing. Ocean Modell., 94, 141-152

Levermann A and 15 others (2014) Projecting Antarctic ice discharge using response functions from SeaRISE ice-sheet models. Earth Syst. Dynamics, 5(2), 271-293

Locarnini RA and 11 others (2013) World Ocean Atlas 2013, Volume 1: Temperature. S Levitus, Ed., A Mishonov Technical Ed.; NOAA Atlas NESDIS 73, U.S. Government Printing Office, Washington, D.C., $40 \mathrm{pp}$

Loose B, Schlosser P, Smethie WM and Jacobs S (2009) An optimized estimate of glacial melt from the Ross Ice Shelf using noble gases, stable isotopes, and CFC transient tracers. J. Geophys. Res., 114(C8)

Meijers AJS (2014) The Southern Ocean in the coupled model intercomparison project phase 5. Philos. Trans. R. Soc. A: Math. Phys. Eng. Sci., 372(2019), 20130296-20130296

Nakayama Y, Timmermann R, Schröder M and Hellmer HH (2014) On the difficulty of modeling Circumpolar Deep Water intrusions onto the Amundsen Sea continental shelf. Ocean Modell., 84, 26-34

Nicholls KW, Østerhus S, Makinson K, Gammelsrød T and Fahrbach E (2009) Ice-ocean processes over the continental shelf of the southern Weddell Sea, Antarctica: a review. Rev. Geophys., 47(3)

Nowicki S and 30 others (2013) Insights into spatial sensitivities of ice mass response to environmental change from the SeaRISE ice sheet modeling project I: Antarctica. J. Geophys. Res.: Earth Surf., 118(2), 1002-1024

Pritchard HD and 5 others (2012) Antarctic ice-sheet loss driven by basal melting of ice shelves. Nature, 484(7395), 502-505 
Raphael MN and 8 others (2015) The Amundsen Sea Low: variability, change and impact on Antarctic Climate. Bull. Am. Meteorol. Soc., 97(1), 111-121

Sallée J-B and 6 others (2013) Assessment of Southern Ocean water mass circulation and characteristics in CMIP5 models: historical bias and forcing response. J. Geophys. Res.: Oceans, 118(4), 1830-1844

Schmidtko S, Heywood KJ, Thompson AF and Aoki S (2014) Multidecadal warming of Antarctic waters. Science, 346(6214), 1227-1231

Screen JA, Gillett NP, Stevens DP, Marshall GJ and Roscoe HK (2009) The role of eddies in the Southern ocean temperature response to the Southern annular mode. J. Clim., 22(3), 806-818

Shu Q, Song Z and Qiao F (2015) Assessment of sea ice simulations in the CMIP5 models. Cryosphere, 9(1), 399-409

Spence P and 5 others (2014) Rapid subsurface warming and circulation changes of Antarctic coastal waters by poleward shifting winds. Geophys. Res. Lett., 41(13), 4601-4610
Stewart AL and Thompson AF (2015) Eddy-mediated transport of warm Circumpolar Deep Water across the Antarctic Shelf Break. Geophys. Res. Lett., 42(2), 432-440

St-Laurent P, Klinck JM and Dinniman JM (2013) On the role of coastal troughs in the circulation of warm circumpolar deep water on Antarctic shelves. J. Phys. Oceanogr., 43(1), 51-64

Timmermann R and Hellmer HH (2013) Southern Ocean warming and increased ice shelf basal melting in the twenty-first and twenty-second centuries based on coupled ice-ocean finiteelement modelling. Ocean Dynam., 63(9-10), 1011-1026

Turner J, Bracegirdle TJ, Phillips T, Marshall GJ and Hosking JS (2013) An initial assessment of Antarctic Sea Ice extent in the CMIP5 models. J. Clim., 26(5), 1473-1484

Whitworth T and Orsi AH (2006) Antarctic Bottom Water production and export by tides in the Ross Sea. Geophys. Res. Lett., 33(12), I12609

Yin J and 5 others (2011) Different magnitudes of projected subsurface ocean warming around Greenland and Antarctica. Nature Geosci., 4(8), 524-528 